\title{
NONLINEAR BOUNDARY VALUE PROBLEM FOR IMPLICIT DIFFERENTIAL EQUATIONS OF FRACTIONAL ORDER IN BANACH SPACES
}

\author{
MOUFFAK BENCHOHRA*,o, SOUFYANE BOURIAH* AND \\ MOHAMED ABDALLA DARWISH ${ }^{\diamond}, \bullet$ \\ *Laboratory of Mathematics, University of Sidi Bel-Abbes \\ P.O. Box 89 Sidi Bel Abbes 22000, Algeria \\ E-mail: benchohra@univ-sba.dz, Bouriahsoufiane@yahoo.fr \\ ${ }^{\circ}$ Department of Mathematics, King Abdulaziz University \\ P.O. Box 80203, Jeddah 21589, Saudi Arabia \\ ${ }^{\diamond}$ Department of Mathematics, Sciences Faculty for Girls \\ King Abdulaziz University, Jeddah, Saudi Arabia \\ E-mail: dr.madarwish@gmail.com \\ -Department of Mathematics, Faculty of Science \\ Damanhour University, Damanhour, Egypt
}

\begin{abstract}
In this paper, we establish sufficient conditions for the existence of solutions for a class of boundary value problem for implicit fractional differential equations with Caputo fractional derivative. We apply the technique of measure of noncompactness and the fixed point theorems of Darbo and Mönch. As an application, two examples are included to show the applicability of our results.

Key Words and Phrases: Boundary value problem, Caputo's fractional derivative, implicit fractional differential equations in Banach space, fractional integral, existence, Gronwall's lemma for singular kernels, measure of noncompactness, fixed point.
\end{abstract}

2010 Mathematics Subject Classification: 26A33, 34A08, 47H10.

Acknowledgement. The authors are grateful to the referee for the careful reading of the paper.

\section{REFERENCES}

[1] S. Abbas, M. Benchohra, On the set of solutions for the Darboux problem for fractional order partial hyperbolic functional differential inclusions, Fixed Point Theory, 14(2013), 253-262.

[2] S. Abbas, M. Benchohra, G.M. N'Guérékata, Topics in Fractional Differential Equations, Springer-Verlag, New York, 2012.

[3] S. Abbas, M. Benchohra, G.M. N'Guérékata, Advanced Fractional Differential and Integral Equations, Nova Science Publishers, New York, 2015.

[4] S. Abbas, M. Benchohra, A.N. Vityuk, On fractional order derivatives and Darboux problem for implicit differential equations, Frac. Calc. Appl. Anal., 15(2012), 168-182.

[5] R.P. Agarwal, M. Meehan, D. O'Regan, Fixed Point Theory and Applications, Cambridge University Press, Cambridge, 2001. 
[6] K.K. Akhmerov, M.I. Kamenskii, A.S. Potapov, A.E. Rodkina, B.N. Sadovskii, Measures of Noncompactness and Condensing Operators, Birkhäuser Verlag, Basel, Bostn, Berlin, 1992.

[7] J. Appell, Implicit functions, nonlinear integral equations and the measure of noncompactness of the superposition operator, J. Math. Anal. Appl., 83(1981), 251-263.

[8] J.M. Ayerbe Toledano, T. Dominguez Benavides, G. Lopez Acedo, Measures of Noncompactness in Metric Fixed Point Theory, Birkhäuser, Basel, 1997.

[9] D. Baleanu, K. Diethelm, E. Scalas, J.J. Trujillo, Fractional Calculus Models and Numerical Methods, World Scientific Publishing, New York, 2012.

[10] D. Baleanu, Z.B. Güvenç, J.A.T. Machado, New Trends in Nanotechnology and Fractional Calculus Applications, Springer, New York, 2010.

[11] D. Baleanu, J.A.T. Machado, A. C.-J. Luo, Fractional Dynamics and Control, Springer, 2012.

[12] J. Banas̀, K. Goebel, Measures of Noncompactness in Banach Spaces, Marcel Dekker, New York, 1980

[13] J. Banas̀, L. Olszowy, Measures of noncompactness related to monotonicity, Comment. Math. (Prace Mat.), 41 (2001), 13-23.

[14] M. Benchohra, F. Berhoun, G.M. N'Guérékata, Bounded solutions for fractional order differential equations on the half-line, Bull. Math. Anal Appl., 146(2012), 62-71.

[15] L. Byszewski, Theorems about existence and uniqueness of solutions of a semilinear evolution nonlocal Cauchy problem, J. Math. Anal. Appl., 162(1991), 494-505.

[16] L. Byszewski, Existence and uniqueness of mild and classical solutions of semilinear functionaldifferential evolution nonlocal Cauchy problem, Selected problems of mathematics, 25-33, 50th Anniv. Cracow Univ. Technol. Anniv. Issue, 6, Krakow Univ. Technol., Krakow, 1995.

[17] G. Darbo, Punti uniti in transformazioni a condominio non compatto, Rend Sem. Mat. Univ. Padova, 24(1955), 84-92.

[18] K. Deng, Exponential decay of solutions of semilinear parabolic equations with nonlocal initial conditions, J. Math. Anal. Appl., 179(1993), 630-637.

[19] K. Diethelm, The Analysis of Fractional Differential Equations, Lecture Notes in Mathematics, Springer, 2010.

[20] A. Granas, J. Dugundji, Fixed Point Theory, Springer-Verlag, New York, 2003.

[21] D.J. Guo, V. Lakshmikantham, X. Liu, Nonlinear Integral Equations in Abstract Spaces, Kluwer Academic Publishers, Dordrecht, 1996.

[22] R. Hilfer, Applications of Fractional Calculus in Physics, World Scientific, Singapore, 2000

[23] A.A. Kilbas, S.A. Marzan, Nonlinear differential equations with the Caputo fractional derivative in the space of continuously differentiable functions, Diff. Equat., 41 (2005), 84-89.

[24] A.A. Kilbas, H.M. Srivastava, J.J. Trujillo, Theory and Applications of Fractional Differential Equations, North-Holland Mathematics Studies, 204, Elsevier Science B.V., Amsterdam, 2006.

[25] K. Kuratowski, Sur les espaces complets, Fund. Math., 15(1930), 301-309.

[26] V. Lakshmikantham, S. Leela, J. Vasundhara, Theory of Fractional Dynamic Systems, Cambridge Academic Publ., Cambridge, 2009.

[27] K.S. Miller, B. Ross, An Introduction to the Fractional Calculus and Differential Equations, John Wiley, New York, 1993.

[28] H. Mönch, Boundary value problems for nonlinear ordinary differential equations of second order in Banach spaces, Nonlinear Anal., 4(1980), 985-999.

[29] I. Podlubny, Fractional Differential Equations, Academic Press, San Diego, 1999.

[30] S.G. Samko, A.A. Kilbas, O.I. Marichev, Fractional Integrals and Derivatives. Theory and Applications, Gordon and Breach, Yverdon, 1993.

[31] X. Su, L. Liu, Existence of solution for boundary value problem of nonlinear fractional differential equation, Appl. Math., 22(2007), no. 3, 291-298.

[32] V.E. Tarasov, Fractional Dynamics: Application of Fractional Calculus to Dynamics of particles, Fields and Media, Springer, Heidelberg, Higher Education Press, Beijing, 2010.

[33] H. Ye, J. Gao, Y. Ding, A generalized Gronwall inequality and its application to a fractional differential equation, J. Math. Anal. Appl., 328(2007), 1075-1081.

[34] K. Yosida, Functional Analysis, 6th ed. Springer-Verlag, Berlin, 1980.

[35] Y. Zhou, Basic Theory of Fractional Differential Equations, World Scientific, Singapore, 2014. 
Received: March 9, 2015; Accepted: April 30, 2015. 